\title{
Correspondence
}

\section{Re: Inserts on Panadol in Sri Lanka Journal of Child Health - June 2003}

Sn Lanka Journal of Child Health, 2003; 32: 116-7

Letters exchanged between the Editors of the Sri Lanka Journal of Child Health and GlaxoSmithKline Ltd on the above subject are given below.

29 July 2003

Mr. Michael Andree

Managing Director

GlaxoSmithKline Ltd.

Dear Mr Andree,

The Editorial Committee of the Sri Lanka College of Paediatricians, at its meeting on the 24th July 2003, discussed with the greatest concern, the advertising inserts put into the above issue of it's journal by your organization. The meeting considered these in the backdrop of several protests voiced by a number of leading Consultant Paediatricians. Regrettably, it was noted that the inserts were sent directly to the printer without prior approval of the Editorial Board.

It was the considered opinion of the Board that the article titled "Lack of hepatic injury after acute paracetamol doses of up to $200 \mathrm{mg} / \mathrm{kg}$ in children" tended to give an entirely erroneous picture of the potential toxicity of paracetamol by not mentioning that it refers to a SINGLE DOSE. Most of the paediatricians in this country have seen several patients with acute liver toxicity following large doses of the drug being given over 2-3 days. Readers could assume, quite understandably, that according to the insert, such high doses are "safe" even when given over several days.

The Board also considered the article on "Ibuprofen, dehydration and renal disorders" in the same set of inserts. On the one hand, the situation alluded to in this article is extremely rare and on the other, the conclusions are not justifiable unless a double-blind controlled study of a reasonable number of patients shows that ibuprofen does contribute towards renal toxicity in the given situation.
It was with great sadness and disappointment that the Board noted that articles such as these should not have appeared in a journal, which has an international circulation. It is an undisputed statement that paracetamol, in the proper dosage, is a useful drug in paediatric practice. It is also a well known fact that your brand of paracetamol has a very good profile of sales in this country. The Board felt that it was not at all necessary to go to these lengths to sell a product that has already established itself as a leader in paediatric prescribing.

With best wishes

Yours sincerely

Dr B J C Perera Dr G N Lucas

Joint Editors of The Sri Lanka Journal of Child Health

29 August 2003

The Joint Editors

Sri Lanka Journal of Child Health

Dear Sirs.

I refer to your letter dated 29.07.2003 addressed to Mr. Michael Andree who is Managing Director. GlaxoSmithKline Pharmaceuticals. This letter has been referred to me as Panadol is marketed by GlaxoSmithKlme Consumer Health Care.

The inserts were approved by the Medical Advisor of GlaxoSmithKline.

I agree that they should have been sent to the editorial board for review before publication. However, our Brand Manager Panadol states that the articles were handed over to the printer direct on the instructions of the Lady in charge of administration at the College of Paediatrics - Wijerama House. Even on the previous occasion we handed over the printed material to the Administrative Officer and in fact there has been no instructions to us to hand over printing material to the Editorial Board. 
Regarding the two articles which have come for specific comment.

Lack of hepatic injury after acute paracetamol doses of up to $200 \mathrm{mg} / \mathrm{kg}$ in children

I agree that a clearer picture would have been given if the heading indicated clearly that what was discussed was a single dose of $200 \mathrm{mg} / \mathrm{kg}$. In fact the text clearly mentions "acute single ingestion".

\section{Ibuprofen, dehydration and renal disorders}

I agree that a double blind controlled study of ibuprofen versus paracetamol would be ideal, to ascertain whether ibuprofen contributes towards renal toxicity in the given situation. The reference was to a

I attach copies of the two main references on which these articles were based. Finally, I am sorry for the embarrassment caused by these articles.

Yours faithfully

K M Dissanayake

Managing Director 